\title{
Synthesis and Selenation of Tandem Multicomponent Condensation Adducts
}

\author{
Guoxiong Hua, Junyi Du, Amy L. Fuller, Kasun S. A. Arachchige, David B. Cordes, Alexandra M. Z. Slawin and J. Derek Woollins*
}

EaStCHEM School of Chemistry, University of St Andrews, Fife, KY16 9ST, UK

Fax +44(1334)463384; Email: jdw3@st-and.ac.uk

\section{Received:}

Abstract: A number of four-component condensation adducts, which were readily obtained from one-pot reaction of aryl carboxylic acids, arylaldehydes, arylamines and $c$ hexylisocyanide, were treated with two equivalents of Woollins' reagent leading to the formation of a series of novel selenoamides with one or two $\mathrm{C}=\mathrm{Se}$ groups, or heterocyclic compounds such as 1,3-selenazole and 1,3-selenazolidin-5-one.

Key words: One-pot reaction / Multicomponent condensation adducts / Woollins' reagent / Selenoamides / Selenium-nitrogen heterocycles

The multicomponent reaction has been applied successfully for the synthesis of different kind of scaffolds and even for efficient construction of even simple heterocycles, ${ }^{1-7}$ a number of substituents can be varied over a broad range, multicomponent reactions often access products of one specific scaffold, limiting the overall chemical diversity. To overcome this shortage, multicomponent reactions were combined with other types of reaction afterwards such as Diels-Alder reactions, ${ }^{8-12}$ click chemistry, ${ }^{13}$ cyclization strategies ${ }^{14}$ and other approaches ${ }^{15-19}$ to generate structural diversity and a high degree of complexity in a minimal number of reaction steps. To our knowledge, however, there is no protocol for the synthesis of chalcogenated amides in such condensation adducts so far. Thus, the development of an efficient approach for the synthesis of chalcoginated adducts remains a challenge.

2,4-Bis(phenyl)-1,3-diselenadiphosphethane-2,4-diselenide $\left[\{\mathrm{PhP}(\mathrm{Se})(\mu-\mathrm{Se})\}_{2}\right]$ (Woollins' reagent), a selenium counterpart of the well-known Lawesson's reagent, has been well documented as an efficient phosphorus-selenium building block or selenation reagent in organic synthetic chemistry in recent years. ${ }^{20}$ The reaction of Woollins' reagent with a variety of organic substrates exhibits a diverse spectrum ranging from simple oxygen-selenium exchange to the formation of complex phosphorus-selenium small- and macro-heterocycles as well as the surprising phosphorus-selenium-free products. ${ }^{21-33}$ In light of our continuing interest in the application of Woollins' reagent in organic synthesis, herein, we report the synthesis of a series of new adducts via tandem four-component condensation, and their corresponding selenation derivatives.

It has been well known that a highly flexible multicomponent reaction between aldehydes, amines, carbonyl compounds, and isocyanides to form $\mathrm{N}$-aryl amines. ${ }^{34,35}$ While searching for new acidic substituents in the Ugi reaction, we thought that a suitable electron-withdrawing group on a carbonyl group could trigger both the imine activation and the irreversible rearrangement in the key step of the reaction.
Indeed, we found that phenylglyoxylic acid reacting with an equivalent of cyclohexyl isocyanide, $p$-chloroaniline and substituted benzaldehydes such as 2,3-dimethoxybenzaldehyde or 3-methoxybenzaldehyde or 4-chlorobenzaldehyde is a very straightforward and efficient four-component reaction. This reaction proceeded smoothly at room temperature in methanol medium within 18 hours to provide the desired $N$-aryl amines 1 $\mathbf{- 3}$ in excellent yields (Scheme 1). ${ }^{36}$

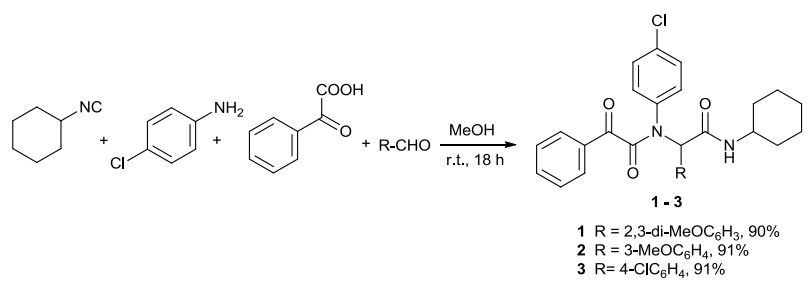

Scheme 1 Formation of four-component condensation adducts $1-3$

The high yield, simple reaction protocol, and originality of this tandem process prompted us to explore the reaction more widely with a variety of substrates. Phenylacetic acid and benzoic acid are proved to be good substrates for this process and reacted with various amines, isocyanides and arylaldehydes. The reaction of phenylacetic acid with one equivalent of cyclohexylisocyanide, 2,3dimethoxybenzaldehyde and 4-bromoaniline gave rise to the expected adduct 4 in $99 \%$ yield under these conditions as shown in Scheme 2. Meanwhile, benzoic acid reacted with equal-molar amount of cyclohexylisocyanide, 4chlorobenzaldehyde and aniline also leading to the corresponding adduct 5 in 99\% yield (Scheme 3). These results showed that benzoic acid is more reactive than phenylacetic acid contributing to the desired products in high yields.

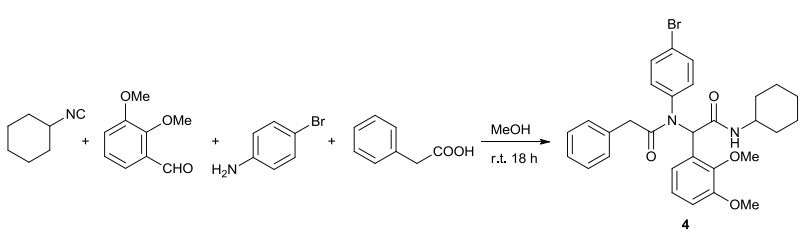

Scheme 2 Formation of four-component condensation adduct 4

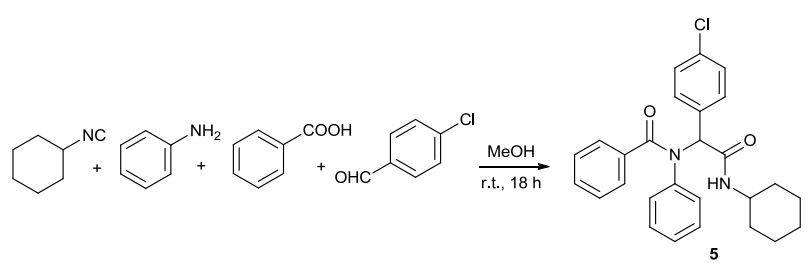

Scheme 3 Formation of four-component condensation adduct 5 
The selenation reactions with Woollins' reagent (WR) were carried out with condensation adducts giving diverse outcomes. Woollins' reagent was obtained by means of the literature method. ${ }^{20}$ Treating $\mathbf{1}-\mathbf{3}$ with two equivalents of Woollins' reagent in refluxing toluene delivered, upon work up in air, the corresponding selenoamides $\mathbf{6}, 7$ and 8 containing two $\mathrm{C}=\mathrm{Se}$ double bond groups in $68 \%, 64 \%$ and $60 \%$ yields, respectively, rather than three $\mathrm{C}=\mathrm{Se}$ double bond groups as shown in Scheme $4 .{ }^{37}$ It is worth noting that one $\mathrm{C}=\mathrm{O}$ group conjoined phenyl ring from starting materials $\mathbf{1}-\mathbf{3}$ was reduced by Woollins' reagent into $\mathrm{CH}_{2}$ group, at the same time as the other two amide $\mathrm{C}=\mathrm{O}$ groups were converted successfully by Woollins' reagent into the corresponding $\mathrm{C}=\mathrm{Se}$ groups leading to selenoamides $\mathbf{6}-\mathbf{8}$. We assume that the five-membered cyclisation ring products were not obtained because of steric hindrance of the two big substituent groups in the bridge N-CH chain between the two $\mathrm{C}=\mathrm{Se}$ groups, and even prolonged reaction time did not lead to the formation of five-membered ring products.

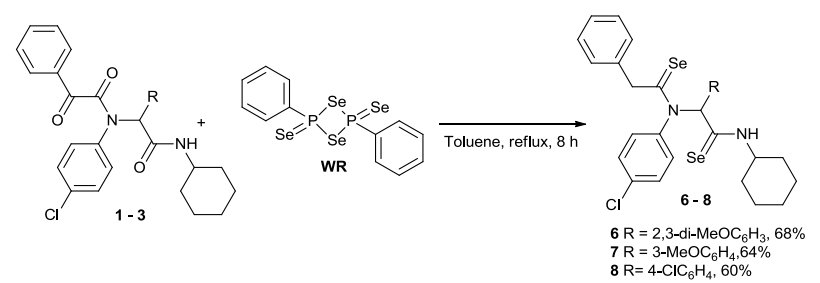

Scheme 4 Selenation of the adducts $\mathbf{1}-\mathbf{3}$ into the selenamides $6-8$

Performing the reaction of amide 4 with two equimolar amounts of Woollins' reagent under the same conditions we found that the expected selenoamide 9 was not formed but selenoamide $\mathbf{1 1}$ with one $\mathrm{C}=\mathrm{Se}$ group was obtained as depicted in Scheme 5. We speculate that amide 4 was originally transformed into selenoamide 9, the latter intermediate then decomposed further into two small pieces: selenoamides $\mathbf{1 0}$ and 11, each bearing one single $\mathrm{C}=\mathrm{Se}$ group and both are thus more stable than the expected intermediate 9. Indeed, compound $\mathbf{1 0}$ was identified in the reaction mixture by ${ }^{77} \mathrm{Se}$ NMR at $\delta_{\mathrm{Se}} 701.8 \mathrm{ppm}$ accompanied by $\delta_{\mathrm{Se}} 541.8 \mathrm{ppm}$ for compound 11. Unfortunately, compound $\mathbf{1 0}$ was not obtained from flash chromatography for full characterization.

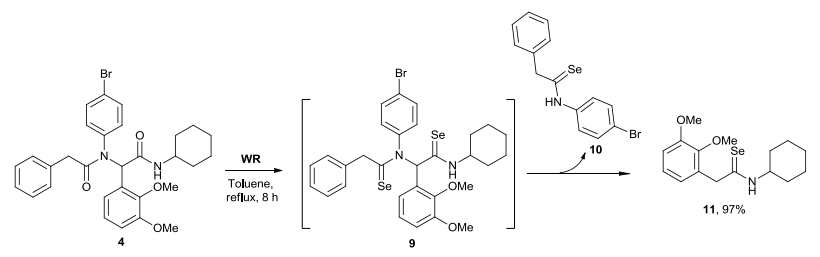

Scheme 5 Selenation of the adducts $\mathbf{4}$ into the selenamide $\mathbf{1 1}$

Surprisingly, the reaction of amide 5 with two equivalents of Woollins' reagent afforded two products: a five-membered ring 1,3-selenazole $\mathbf{1 2}$ and a five-membered ring 1,3-selenazolidin5 -one $\mathbf{1 3}$ in $32 \%$ and $24 \%$ isolated yields, respectively (Scheme 6). We propose that 1,3-selenazole $\mathbf{1 2}$ might derive from an unstable fully selenated intermediate $\mathbf{A}$ by the cyclization, meanwhile 1,3-selenazolidin-5-one $\mathbf{1 3}$ comes from the unstable half selenated intermediate $\mathbf{B}$, followed by a cyclization, a reduction and an enolization into intermediate $\mathbf{C}$ and finally tautomerization leading to $\mathbf{1 3}$. We recognize that this mechanism is speculative but note that similar analogous sulfur products have been documented in the reaction of di-amides with Lawesson's reagent. ${ }^{38-40}$

All new compounds $\mathbf{1}-\mathbf{8}, \mathbf{1 1}$ and $\mathbf{1 3}$ were fully characterized by multi-nuclear $\left({ }^{1} \mathrm{H},{ }^{13} \mathrm{C}, \quad{ }^{77} \mathrm{Se}\right) \quad \mathrm{NMR}$ spectroscopy, IR spectroscopy and mass spectroscopy. All compounds showed the anticipated $[\mathrm{M}]^{+}$or $[\mathrm{M}+\mathrm{H}]^{+}$peak in their mass spectra and satisfactory accurate mass measurement. The ${ }^{13} \mathrm{C}$ chemical shifts in compounds $\mathbf{1}-\mathbf{5}$ in the range 167.6 - $190.6 \mathrm{ppm}$ are typical for $\mathrm{C}=\mathrm{O}$ double bonds in amides. The ${ }^{13} \mathrm{C}$ chemical shifts for $\mathrm{C}=\mathrm{Se}$ in compounds 6 being at $\delta_{\mathrm{C}}=$ 204.4 and $202.8 \mathrm{ppm}, 7$ at $\delta_{\mathrm{C}}=202.6$ and $201.5 \mathrm{ppm}$, and 8 at $\delta_{\mathrm{C}}=198.8$ and $198.3 \mathrm{ppm}$ are considerably lower than that in the five- or six-membered heteocyclic compounds containing $\mathrm{C}=$ Se double bonds $\left(\delta_{\mathrm{C}}=287-294 \mathrm{ppm}\right)^{41}$ and are marginally lower than that in the reported selenoamides $\left(\delta_{\mathrm{C}}=203-218\right.$ ppm). ${ }^{41-44}$ Meanwhile, in compound 11, the ${ }^{13} \mathrm{C}$ chemical shift for $\mathrm{C}=\mathrm{Se}$ is $204.4 \mathrm{ppm}$, falling within the range are typical for selenoamides. ${ }^{41,42}$ The ${ }^{77} \mathrm{Se}$ chemical shifts for $\mathrm{C}=\mathrm{Se}$ groups $\mathbf{6}-$ 8 and 11 range from $\delta_{\mathrm{Se}}=540.1$ to $546.9 \mathrm{ppm}$ and are significantly lower than that in primary aryl substituted selenoamides (average value ca. $631 \mathrm{ppm})^{43}$ and in methyl dimethyldiselenocarbamate $\left(\delta_{\mathrm{Se}}=602 \mathrm{ppm}\right),{ }^{44}$ however, these values are drastically shifted to high-field, compared to that in the six-membered systems such as 1-thia-3,3,5,5-tetramethyl-4cyclohexanselenone $\left(\delta_{\mathrm{Se}}=2131 \mathrm{ppm}\right)$ and selenofenchone $\left(\delta_{\mathrm{Se}}\right.$ $=1613 \mathrm{ppm}) .{ }^{45}$ With respect to heterocycles $\mathbf{1 2}$ and $\mathbf{1 3}$, the ${ }^{13} \mathrm{C}$ chemical shifts for the $\mathrm{C}=\mathrm{O}$ in $\mathbf{1 3}$ being at $\delta_{\mathrm{C}}=198.4 \mathrm{ppm}$ falls with the range of 160-220 ppm for carbonyl carbon atoms. In 12 the ${ }^{77} \mathrm{Se}$ NMR spectrum displays a singlet signal at $\delta_{\mathrm{Se}}=$ 707.9 ppm, comparable to related selenium-nitrogen heterocyclic compounds. ${ }^{46}$

Recrystallization by diffusion of hexane into dichloromethane solutions in air at room temperature gave crystals of 1, 2, 4, 6, 11 and 13 suitable for X-ray diffraction studies as shown in Figures 1 - 2 and Figures S1 - S6, with structural data given in Tables S1 and S2. Compounds $\mathbf{1}$ and $\mathbf{2}$ crystallize in the triclinic space group $P-1$, meanwhile, compound 4 in the monoclinic space group $P 2_{1 / c}$. It is noted that compound $\mathbf{1}$ was found to be co-crystallized with one molecule of dichloromethane. The structural conformations of 1, 2 and 4 are arranged with the three phenyl rings being inclined to one another at $55.64^{\circ}, 71.98^{\circ}$ and $53.26^{\circ}$ in $\mathbf{1}$; $63.35^{\circ}, 64,75^{\circ}$ and $61.90^{\circ}$ in 2 , and $85.7^{\circ}, 43.8^{\circ}$ and $52.2^{\circ}$ in 4 . The distances of $\mathrm{C}(2)-\mathrm{N}(1)$ and $\mathrm{C}(5)-\mathrm{N}(4)$ in $\mathbf{1}(1.329(4) \AA$ and $1.339(4) \AA)$, in 2 (1.346(5) $\AA$ and $1.342(4) \AA$ ) and in 4 $(1.346(7) \AA$ and $1.365(7) \AA)$ are quite similar to each other, indicating some multiple bond character present due to the effect of the adjacent $\mathrm{C}=\mathrm{O}$ double bond. 


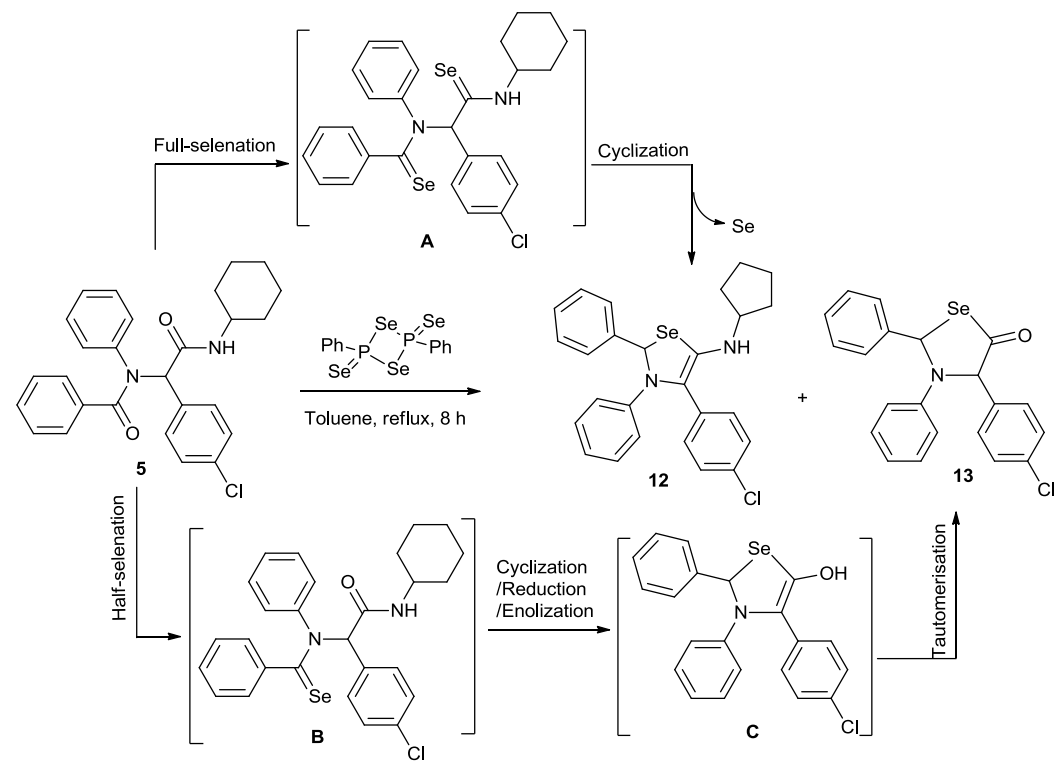

Scheme 6 Selenation of the adducts 5 into the heterocycles 12 and $\mathbf{1 3}$

The X-ray analysis reveals that the two amide groups within all three diamides 1, 2 and $\mathbf{4}$ adopt an antiparallel conformation relative to the quaternary carbon and there is no intramolecular hydrogen bonding. ${ }^{47}$ However, there are very similar intermolecular hydrogen bond interaction between the amide hydrogen atoms of one molecule and the oxygen atom of the amide group of another molecule leading to the formation of a faked dimeric 'fourteen-membered ring' conformations in 1, 2 and $\mathbf{4}$ as shown in Figure 1. The $\mathrm{N}-\mathrm{H} \cdots \mathrm{O}$ lengths range from 2.106 to $2.164 \AA$ and $\mathrm{N} \cdots \mathrm{O}$ distances range from $2.937(7)$ to $3.058(4) \AA$, accompanied by the $\mathrm{N}-\mathrm{H} \cdots \mathrm{O}$ angles of $157.15^{\circ}$, $154.68^{\circ}$ and $157.23^{\circ}$ close to a typical $\mathrm{N}-\mathrm{H} \cdots \mathrm{O}=\mathrm{C}$ interaction. ${ }^{48}$

Based on the results of X-ray analysis, the two amide groups within all three diamides $\mathbf{1}, 2$ and $\mathbf{4}$ adopt an antiparallel conformation relative to quaternary carbon and there is no intramolecular hydrogen bonding. ${ }^{47}$ However, there are very similar intermolecular hydrogen bond interaction between the proton of amide group of one molecule and the $\mathrm{O}$ atom of amide group of other molecule leading to the formation of a robust three-dimension 'fourteen-membered ring' framework, held in place by the basic dimer unit in structures of $\mathbf{1 , 2}$ and $\mathbf{4}$ as shown in Figure 1. The $\mathrm{N}-\mathrm{H} \cdots \mathrm{O}$ lengths ranging from 2.106 to $2.163 \AA$ and $\mathrm{N} \cdots \mathrm{O}$ distances ranging from 2.937 to $3.068 \AA$, accompanied by the $\mathrm{N}-\mathrm{H} \cdots \mathrm{O}$ angle holding respective $157.15^{\circ}$, $154.68^{\circ}$ and $157.23^{\circ}$ are nearly falling within a typical $\mathrm{N}$ $\mathrm{H} \cdots \mathrm{O}=\mathrm{C}$ interaction of good geometry. ${ }^{48}$
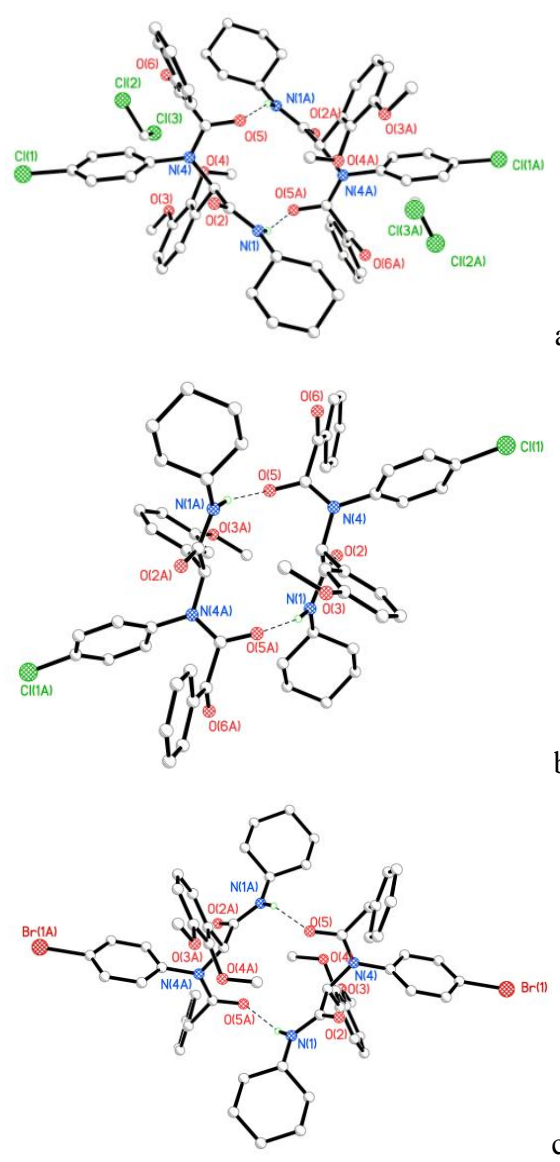

Figure 1 Molecular structures of 1 (a), 2 (b) and 4 (c) show the intermolecular $\mathrm{N}-\mathrm{H} \cdots \mathrm{O}$ hydrogen bonds to form fourteenmembered rings.

Interestingly, $\mathbf{6}$ co-crystallizes in the triclinic space group $P$ 1 with two different molecules (namely, the selenoamide $\mathbf{1 4}$ and the solvated dichloromethane) in the unit cell (Figure 2). Selenoamide $\mathbf{1 4}$ is apparent one of two decomposed fragments 14 and 15 from the selenoamide 6 during the crystallization process as depicted in Scheme 7. Indeed, we did not find any 
trace of compounds $\mathbf{1 4}$ and $\mathbf{1 5}$ in either the crude reaction mixture or the original compound $\mathbf{6}$ by multi-NMR spectra. Furthermore, this co-crystallization prevented characterization of compounds 14 and 15 by multi-NMR and mass spectroscopy. In $\mathbf{6}$, the selenium atom is almost co-planar with a phenyl ring plane (C3-C4-C5-C6-C7-C8). Whilst, the C1-N1$\mathrm{Se} 1$ unit in $\mathbf{1 4}$ is coplanar with $\mathrm{C} 32$, the dihedral angle between the phenyl ring plane and the $\mathrm{C} 31-\mathrm{Se} 2-\mathrm{N} 3$ mean plane is $85.3^{\circ}$ as a consequence of the strong steric effect imposed by the two ortho- and meso- methoxyl groups. Notably, the $\mathrm{C}=\mathrm{Se}$ double bond and $\mathrm{C}-\mathrm{N}$ single bond lengths in the amide functional groups are 1.814(8) and 1.826(10) $\AA$, and 1.329(12) and 1.296(11) $\AA$ for molecules $\mathbf{1 4}$ and 6, respectively, comparable to the values in the known selenoamides $[1.81(5)-1.856(4) \AA$ for $\mathrm{C}=\mathrm{Se}$ double bonds and $1.270(7)-1.324(8) \AA$ for $\mathrm{C}-\mathrm{N}$ single bonds]. ${ }^{42,49}$ Interestingly, intramolecular $\mathrm{N}-\mathrm{H} \cdots \mathrm{O}$ hydrogen bonding was observed in $\mathbf{6}$ and $\mathbf{1 4}$ to form faked seven-membered ring conformations. The $\mathrm{N}-\mathrm{H} \cdots \mathrm{O}$ distances (2.09 and $2.15 \AA$ ), and $\mathrm{N} \cdots \mathrm{O}$ distances (2.920 and $3.031 \AA$ ) and the $\mathrm{N}-\mathrm{H} \cdots \mathrm{O}$ angles $\left(157.46\right.$ and $\left.175.19^{\circ}\right)$ are comparable to those in molecules $\mathbf{1}, \mathbf{2}$ and $\mathbf{4}$.

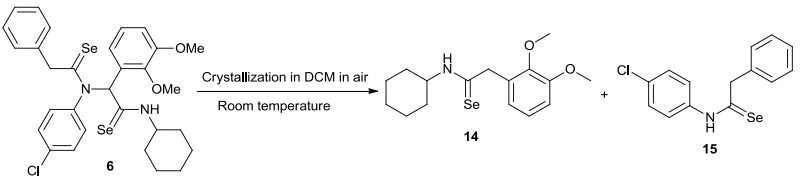

Scheme 7 Decomposed products 14 and 15 of the selenamide 6 during crystallization process

Compound 11 co-crystallizes in the triclinic space group $P-1$ with another solvated molecule of $n$-hexane in the unit cell as depicted in Figure S5. The $\mathrm{C}=\mathrm{Se}$ double bond and $\mathrm{C}-\mathrm{N}$ single bond distances [1.829(9) and 1.319(9) $\AA$, respectively] are in good agreement with the literature values for the normal $\mathrm{C}=\mathrm{Se}$ double bond distances $[1.81(5)$ to $1.856(4) \AA]$ and $\mathrm{C}-\mathrm{N}$ distances $[1.270(7)$ to $1.324(8) \AA]$ in primary selenoamides. ${ }^{42,49}$ The selenoamide functionality is not particularly coplanar with either the peripheral aryl backbone or cyclohexane ring, with the dihedral angles between the $\mathrm{Se}(1)-\mathrm{C}(1)-\mathrm{N}(1)$ mean plane and the aryl plane/the cyclohexane mean plane being 88.84 and $66.91^{\circ}$, respectively, whilst two peripheral aryl plane and cyclohexane mean plane declines up to $32.15^{\circ}$ each other. Interestingly, the typical $\mathrm{N}-\mathrm{H} \cdots$ Se hydrogen bonding was not observed as previous reports on the similar selenoamides, ${ }^{40,41}$ however, there is a strong $\mathrm{N}-\mathrm{H} \cdots \mathrm{O}$ hydrogen bond interaction in the structure of 11. The $\mathrm{O}$ atoms on the ortho-position $\mathrm{CH}_{3} \mathrm{O}$ group in the phenyl ring act as hydrogen bond acceptors towards the $\mathrm{N}-\mathrm{H}$ groups of a neighbouring molecule leading to the 'fourteen-membered ring heterocyclic' architecture as shown in Figure 4. The $\mathrm{N}-\mathrm{H} \cdots \mathrm{O}$ and $\mathrm{N} \cdots \mathrm{O}$ distances are $2.12 \AA$ and 2.992(10) $\AA$, respectively, accompanied by an $\mathrm{N}-\mathrm{H} \cdots \mathrm{O}$ angle of $171.9^{\circ}$.
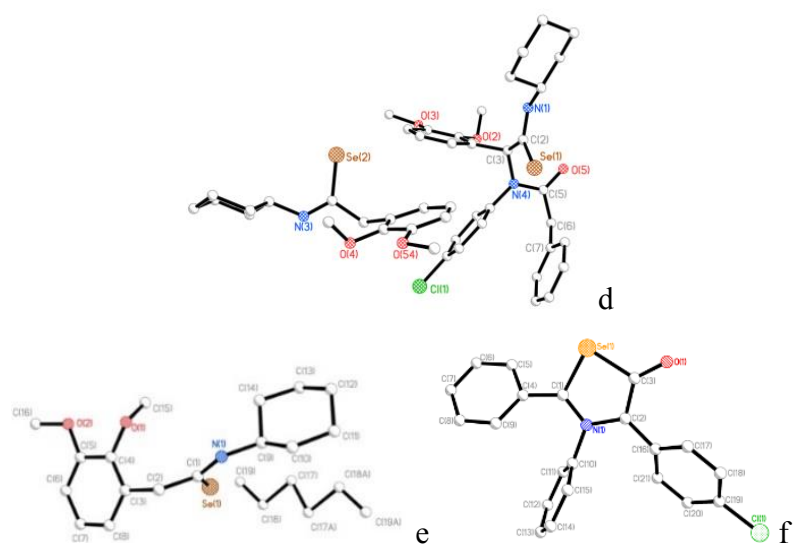

Figure 2 Molecular structures of 6 co-crystallized with 14 (d), 11 (e) and 13 (f) (Hydrogen atoms at carbon atoms omitted for clarity).

Compound $\mathbf{1 3}$ crystallizes in the monoclinic space group $P{ }_{l} / c$ (Figure S6). Surprisingly, we have found no published Xray crystal structure data on this newly formed Se-C-N-C-C ring backbone. The five-membered Se1-C1-N1-C2-C3 ring is almost perfectly planar, the $\mathrm{O}$ atom being $0.007 \AA$ out of the plane. The three phenyl rings attaching to the five-membered ring orientate differently each other. The dihedral angles between the five-membered ring plane and three phenyl rings are $35.90,68.91$ and $38.71^{\circ}$, respectively. Furthermore, due to the rotational symmetry, this leads to the planes of their phenyl rings being inclined by $57.60,68.96$ and $71.47^{\circ}$ with respect to each other. Two different C-Se distances [1.849(3) and 1.946(3) $\AA]$ show one $\mathrm{C}-\mathrm{Se}$ bond having somewhat double bond character, which is close to the values found in selenadiazoles ${ }^{23,29,50}$ and the other C-Se bond reveals its typical single bond nature ( $c a .1 .94 \AA$ ). The two C-N bonds [1.341(3) and $1.403(3) \AA]$ also demonstrate multiple/single bond distances.

In summary, a series of new adducts were prepared by using multicomponent condensation reaction from readily available substrates. The newly formed adducts were reacted with Woollins' reagent giving rise to a variety of novel selenoamides and selenium-nitrogen heterocyclic compounds in good yields. All new products were fully characterized by multi-NMR and mass spectroscopy and six representative X-ray structures were elucidated successfully. The solid state structures of adducts $\mathbf{1}$, $\mathbf{2}$ and $\mathbf{4}$ display intermolecular $\mathrm{N}-\mathrm{H} \cdots \mathrm{O}$ hydrogen bonds leading to dimeric fourteen-membered ring architectures. The structure of selenoamide 6 co-crystallizes with one of its two decomposed products. Surprisingly, typical $\mathrm{N}-\mathrm{H} \cdots$ Se hydrogen bonding in the structure of selenoamide $\mathbf{1 1}$ was not observed as previous reports on the similar selenoamides, instead, there is the strong intermolecular $\mathrm{N}-\mathrm{H} \cdots \mathrm{O}$ hydrogen bond interaction present. The newly formed five-membered ring Se-C-N-C$\mathrm{C}(=\mathrm{O})$ in heterocyclic compound $\mathbf{1 3}$ is almost perfectly planar. The synthesis and X-ray single crystal structures of a series of new selenoamides and 1,3-selenazolic compounds provide a valuable addition to the library of selenium-containing heteroatom compounds known. 
Supporting Information for this article is available online at http://www.thieme-connect.com/ejournals/toc/synlett.

X-ray data for compounds $1,2,4,6,11$ and 13 CCDC 1017055-1017060 can be obtained free of charge via www.ccdc.cam.ac.uk/conts/retrieving.html or from the Cambridge Crystallographic Data centre, 12 Union Road, Cambridge CB2 1EZ, UK; fax (+44) 1223-336-033; e-mail: deposit@ccdc.cam.ac.uk.

\section{References and Notes}

(1) Domling, A.; Ugi, I. Angew. Chem. Int. Ed. 2000, 39, 3168-3210.

(2) Domling, A. Chem. Rev. 2006, 106, 17-89.

(3) Domling, A.; Wang, W.; Wang, K. Chem. Rev. 2012, 112, 3083-3135.

(4) Heijden, G.; Ruijter, E.; Orru, R. V. A. Synlett 2013, 24, 666-685.

(5) de Greef, R. V. A.; Orru, M. Synthesis 2003, 1471-1499.

(6) Sunderhaus, J. D.; Martin, S. F. Chem. Eur, J. 2009, 15, 1300-1308.

(7) Yu, J.; Shi, F.; Gong, L. Z. Acc. Chem. Res. 2011, 44, 1156-1171.

(8) Paulvannan, K. Tetrhedron Lett. 1999, 40, 1851-1854.

(9) Lee, D.; Sello, J. K.; Schreiber, S. L. Org. Lett. 2000, 2, 709-712.

(10) Wright, D. L.; Robotham, C. V.; Aboud, K. Tetrahedron Lett. 2002, 43, 943-946.

(11) Sello, J. K.; Andreana, P. R.; Lee, D.; Schreiber, S. L. Org. Lett. 2003, 5, 4125-4127.

(12) Lu, K.; Luo, T.; Xiang, Z.; You, Z.; Fathi, R.; Chen, J.; Yang, Z. J. Comb. Chem. 2005, 7, 958-967.

(13) Khanetskyy, B.; Dallinger, D.; Kappe, C. O. J. Comb. Chem. 2004, 6, 884-892.

(14) Sunderhaus, J. D.; Martin, S. F. Chem. Eur. J. 2009, 15, 1300-1308.

(15) Groenendaal, B.; Ruijter, E.; Orru, R. V. A. Chem. Commun. 2008, 5474-5489.

(16) Groenendaal, B.; Vugts, D. J.; Schmitz, R. F.; de Ksnter, F. J. J.; Ruijter, E.; Groen, M. B.; Orru, R. V. A. J. Org. Chem. 2008, 73, 719-722.

(17) Pirali, T.; Tron, G. C.; Zhu, J. Org. Lett. 2006, 8, 41454148.

(18) Pirali, T.; Tron, G. C.; Masson, G.; Zhu, J. Org. Lett. 2007, 9, 5275-5278.

(19) Elders, N.; Schmitz, R. F.; de Kannter, F. J. J.; Ruijter, E.; Groen, M. B.; Orru, R. V. A. J. Org. Chem. 2007, 72, 6135-6142.

(20) Gray, P.; Bhattacharyya, P.; Slawin, A. M. Z.; Woollins, J. D. Chem. Eur. J. 2005, 11, 6221-6227.

(21) For reviews, see (a) Hua, G.; Woollins, J. D. Angew. Chem., Int. Ed. 2009, 48, 1368-1377; (b) Woollins, J. D. Synlett 2012, 1154-1169.

(22) Hua, G.; Henry, J. B.; Li, Y.; Mount, A. R.; Slawin, A. M. Z.; Woollins, J. D. Org. Biomol. Chem. 2010, 8, 16551660 .

\section{Acknowledgements}

We are grateful to the University of St Andrews for financial support and the EPSRC National Mass Spectrometry Service Centre (Swansea) for mass spectral measurements.

(23) Hua, G.; Li, Y.; Fuller, A. L.; Slawin, A. M. Z.; Woollins, J. D. Eur. J. Org. Chem. 2009, 1612-1618.

(24) Hua, G.; Li, Y.; Fuller, A. L.; Slawin, A. M. Z.; Woollins, J. D. New J. Chem. 2010, 34, 1565-1571.

(25) Hua, G.; Li, Y.; Fuller, A. L.; Slawin, A. M. Z.; Woollins, J. D. Eur. J. Org. Chem. 2010, 2707-2615.

(26) Hua, G.; Li, Y.; Fuller, A. L.; Slawin, A. M. Z.; Woollins, J. D. Polyhedron 2011, 30, 805-808.

(27) Hua, G.; Li, Y.; Fuller, A. L.; Slawin, A. M. Z.; Woollins, J. D. Eur. J. Org. Chem. 2011, 3067-3073.

(28) Hua, G.; Griffin, J. M.; Ashbrook, S. E.; Slawin, A. M. Z.; Woollins, J. D. Angew. Chem. Int. Ed. 2011, 50, 41234126.

(29) Hua. G.; Cordes, D. B.; Li, Y.; Slawin, A. M. Z.; Woollins, J. D. Tetrahedron Lett. 2011, 52, 3311-3314.

(30) Hua, G.; Li, Y.; Fuller, A. L.; Slawin, A. M. Z.; Woollins, J. D. Synlett 2012, 23, 2453-2458.

(31) Hua, G.; Woollins, J. D. Polyhedron 2012, 42, 190-195.

(32) Hua, G.; Li, Y.; Slawin, A. M. Z.; Woollins, J. D. Synlett 2012, 23, 1170-1174.

(33) Hua, G.; Randall, R. A. M.; Slawin, A. M. Z.; Cordes, D. B.; Crawford, L.; Bühl, M.; Woollins, J. D. Chem. Commun. 2013, 49, 2619-2621.

(34) Ugi, I. Angew. Chem. Int. Ed. 1982, 21, 810-819.

(35) Dömling, A.; Ugi, I. Angew. Chem. Int. Ed. 2000, 39, 3168-3210.

(36) Preparation of $\mathrm{N}$-(4-Chlorophenyl)- $\mathrm{N}$-(1-(4chlorophenyl)-2-(cyclohexylamino)-2-oxoethyl)-2-oxo2-phenyl-acetamide (3). General procedure: A mixture of cyclohexylisocyanide $(1.100 \mathrm{~g}, 10.0 \mathrm{mmol})$ and 4chlorobenzaldehyde (1.362 g, $10.0 \mathrm{mmol})$ and 4chloroaniline $(1.276 \mathrm{~g}, 10 \mathrm{mmol})$ and phenylglyoxylic acid $(1.406 \mathrm{~g}, 10.0 \mathrm{mmol})$ in $20 \mathrm{~mL}$ of dry $\mathrm{CH}_{3} \mathrm{OH}$ was stirred at room temperature for $18 \mathrm{~h}$. The mixture was then concentrated on $c a .5 \mathrm{~mL}$ and purified by silica gel column (eluented by $1: 9$ ethyl acetate / dichloromethane) to give $4.60 \mathrm{~g}$ of the titled compound as a white solid in $91 \%$ yield. M.p. $196-198^{\circ} \mathrm{C}$. Selected IR $\left(\mathrm{KBr}, \mathrm{cm}^{-1}\right)$ : 1686(s), 1660(s), 1536(s), 1490(s), 1337(m), 1227(s), 1094(s), 1015(s), 807(m), 693(s),583(m), 563(m), 433(m). ${ }^{1} \mathrm{H}$ NMR $\left(\mathrm{CD}_{2} \mathrm{Cl}_{2}, \delta\right), 7.94(\mathrm{~d}, J(\mathrm{H}, \mathrm{H})=7.2 \mathrm{~Hz}, 2 \mathrm{H}, \mathrm{Ar}-$ $\mathrm{H}), 7.60(\mathrm{~d}, J(\mathrm{H}, \mathrm{H})=7.2 \mathrm{~Hz}, 2 \mathrm{H}, \operatorname{Ar}-\mathrm{H}), 7.49-7.44(\mathrm{~m}$, $3 \mathrm{H}, \operatorname{Ar}-\mathrm{H}), 7.21(\mathrm{~d}, J(\mathrm{H}, \mathrm{H})=7.2 \mathrm{~Hz}, 2 \mathrm{H}, \mathrm{Ar}-\mathrm{H}), 7.10(\mathrm{~d}$, $J(\mathrm{H}, \mathrm{H})=7.2 \mathrm{~Hz}, 2 \mathrm{H}, \mathrm{Ar}-\mathrm{H}), 6.98(\mathrm{~d}, J(\mathrm{H}, \mathrm{H})=7.2 \mathrm{~Hz}, 2 \mathrm{H}$, $\mathrm{Ar}-\mathrm{H}), 6.16(\mathrm{~s}, 1 \mathrm{H}, \mathrm{CH}), 5.60(\mathrm{~d}, J(\mathrm{H}, \mathrm{H})=7.7 \mathrm{~Hz}, 1 \mathrm{H}$, $\mathrm{NH}), 3.88-3.81$ (m, 1H, cyclohexyl-H), 1.98-1.01 (m, $11 \mathrm{H}$, cyclohexyl-H) ppm. ${ }^{13} \mathrm{C}$ NMR $\left(\mathrm{CD}_{2} \mathrm{Cl}_{2}, \delta\right), 190.4$ $(\mathrm{C}=\mathrm{O}), 167.7(\mathrm{C}=\mathrm{O}), 167.3(\mathrm{C}=\mathrm{O}), 135.3,135.0,134.7$, $133.1,132.9,132.1,131.8,129.7,129.0,128.9,128.8$, 64.0, 49.3, 32.8, 25.5, $24.9 \mathrm{ppm}$. MS $\left(\mathrm{CI}^{+}, \mathrm{m} / \mathrm{z}\right), 509$ 
$[\mathrm{M}+\mathrm{H}]^{+}$. Accurate mass measurement $\left[\mathrm{CI}^{+}, \mathrm{m} / \mathrm{z}\right]$ : 509.1386 $[\mathrm{M}+\mathrm{H}]^{+}$, calculated mass for $\mathrm{C}_{28} \mathrm{H}_{26} \mathrm{Cl}_{2} \mathrm{~N}_{2} \mathrm{O}_{3}$ : 509.1393.

(37) Preparation of $\mathrm{N}$-(4-Chlorophenyl)- $\mathrm{N}$-(2(cyclohexylamino)-1-(2,3-dimethoxyphenyl)-2selenoxoethyl)-2-phenylethaneselenoamide (6). General procedure: A mixture of $N$-(4-Chlorophenyl)- $N$-(2(cyclohexylamino)-1-(2,3-dimethoxyphenyl)-2-oxoethyl)2-oxo-2-phenyl-acetamide $(0.534 \mathrm{~g}, 1.0 \mathrm{mmol})$ and Woollins' reagent $(1.07 \mathrm{~g}, 2.0 \mathrm{mmol})$ in $20 \mathrm{~mL}$ of dry toluene was refluxed for $8 \mathrm{~h}$. A brown suspension was formed. Upon cooling to room temperature, the mixture was filtered to remove insoluble solid and the filtrate was dried in vacuum. Then, the residue was dissolved in $c a$. 1 $\mathrm{mL}$ of dichloromethane and was purified by silica gel column (eluented by $1: 5$ ethyl acetate / dichloromethane) to give $0.440 \mathrm{~g}$ as a pale yellow solid in $68 \%$ yield. M.p. $>210^{\circ} \mathrm{C}$ (Dec.). Selected IR (KBr, $\left.\mathrm{cm}^{-1}\right): 1649(\mathrm{~s}), 1647(\mathrm{~s})$, 1587(m), 1536(m), 1483(vs), 1451(s), 1430(s), 1273(s), 1223(m), 1168(m), 1088(s), 1003(s), 749(s), 706(s). ${ }^{1} \mathrm{H}$ NMR $\left(\mathrm{CD}_{2} \mathrm{Cl}_{2}, \delta\right), 8.87(\mathrm{~d}, J(\mathrm{H}, \mathrm{H})=8.5 \mathrm{~Hz}, 1 \mathrm{H}$, Ar-H), 7.98-6.21 (m, 11H, Ar-H), $6.21(\mathrm{~s}, 1 \mathrm{H}, \mathrm{CH}), 5.70(\mathrm{~d}$, $J(\mathrm{H}, \mathrm{H})=8.0 \mathrm{~Hz}, 1 \mathrm{H}, \mathrm{NH}), 3.84\left(\mathrm{~s}, 3 \mathrm{H}, \mathrm{OCH}_{3}\right), 3.81-3.79$ $\left(\mathrm{m}, 1 \mathrm{H}\right.$, cyclohexyl-H), $3.76\left(\mathrm{~s}, 3 \mathrm{H}, \mathrm{OCH}_{3}\right), 3.40(\mathrm{~s}, 2 \mathrm{H}$, $\left.\mathrm{CH}_{2}\right), 2.08-0.85$ (m, $10 \mathrm{H}$, cyclohexyl-H) ppm. ${ }^{13} \mathrm{C}$ NMR $\left(\mathrm{CD}_{2} \mathrm{Cl}_{2}, \delta\right), 204.4(\mathrm{C}=\mathrm{Se}), 202.8(\mathrm{C}=\mathrm{Se})$, 152.6, 148.2, $140.7,131.0,129.3,129.2,128.5,128.4,128.1,126.9$, $124.5,123.6,122.6,113.5,74.0,66.9,55.8,53.5,36.8$, 25.4, 24.4 ppm. ${ }^{77} \mathrm{Se} \mathrm{NMR}\left(\mathrm{CD}_{2} \mathrm{Cl}_{2}, \delta\right), 546.0$ and 542.5 ppm. MS $\left(\mathrm{CI}^{+}, \mathrm{m} / \mathrm{z}\right), 649[\mathrm{M}+\mathrm{H}]^{+}$. Accurate mass measurement $\left[\mathrm{CI}^{+}, \mathrm{m} / \mathrm{z}\right]: 649.0629[\mathrm{M}+\mathrm{H}]^{+}$, calculated mass for $\mathrm{C}_{30} \mathrm{H}_{33} \mathrm{ClN}_{2} \mathrm{O}_{2} \mathrm{Se}_{2} \mathrm{H}$ : 649.0635 .

(38) Jenny, C.; Heimgartner, H. Helv. Chim. Acta 1986, 69, 374-388.

(39) Jenny, C.; Heimgartner, H. Helv. Chim. Acta 1987, 70, 1001-1011.

(40) Jenny, C.; Heimgartner, H. Helv. Chim. Acta 1989, 72, 1639-1646.

(41) Cullen, E. R.; Guziec, Jr. F. S.; Murphy, C. J.; Wong, T. C.; Andersen, K. K. J. Chem. Soc., Perkin 2, 1982, 473476.

(42) Hua, G.; Li, Y.; Slawin, A. M. Z.; Woollins, J. D. Org. Lett. 2006, 8, 5251-5254.

(43) Li, Y.; Hua, G.; Slawin, A. M. Z.; Woollins, J. D. Molecules 2009, 14, 884-892.

(44) Kobayashi, K.; Kukada,H.; Kikuchi, K.; Ikemoto, I. Bull. Chem. Soc. Jpn. 1986, 59, 1741-1746.

(45) Cullen, E. R.; Guziec, Jr. F. S.; Murphy, C. J.; Wong, T. C.; Andersen, K. K. J. Am. Chem. Soc. 1981, 103, 70557057.

(46) Geisler, K.; Pferffer, W. D.; Kunzler, A.; Below, H.; Bulka, E.; Langer, P. Synthesis 2004, 875-884.

(47) Usha, R.; Venkatesan, K. Acta Crystallogr., Sect. B: Struct. Crystallogr. Cryst. Chem. 1979, B35, 2730-2732.

(48) Baker, E. R.; Hubbard, R. E. Prog. Biophys. Mol. Biol. 1984, 44, 97-179.

(49) Lai, L. L.; Reid, D. H. Synthesis 1993, 870-872.

(50) Cordes, D. B.; Hua, G.; Slawin, A. M. Z.; Woollins, J. D. Acta Cryst. 2011, C67, o509-o514. 


\section{Graphical abstract}

\section{Synthesis and Selenation of Tandem Multicomponent Condensation Adducts}

Guoxiong Hua, Junyi Du, Amy L. Fuller, Kasun S. A. Arachchige, David B. Cordes, Alexandra M. Z. Slawin and J. Derek Woollins*
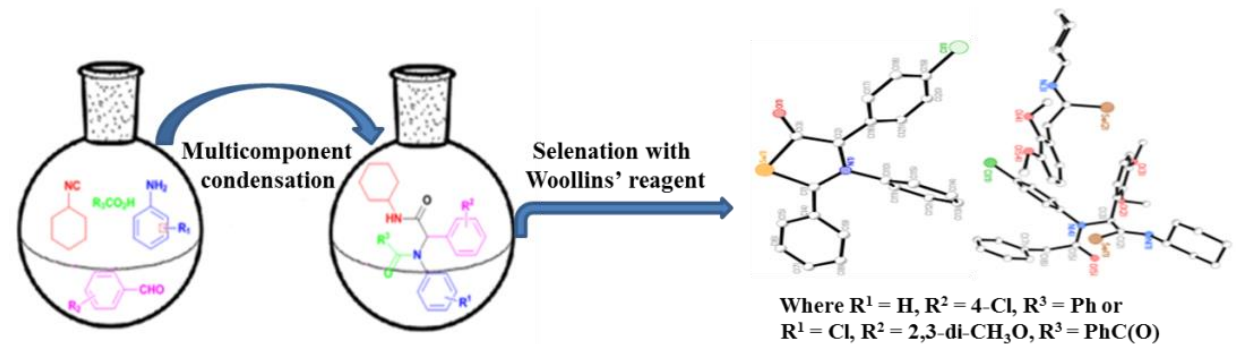

Where $\mathbf{R}^{1}=\mathbf{H}, \mathbf{R}^{2}=4-\mathrm{Cl}, \mathbf{R}^{3}=\mathbf{P h}$ or $\mathbf{R}^{1}=\mathrm{Cl}, \mathbf{R}^{2}=\mathbf{2 , 3}$-di- $\mathrm{CH}_{3} \mathrm{O}, \mathbf{R}^{3}=\operatorname{PhC}(\mathrm{O})$

Novel selenium compounds were obtained through four-component-one-pot condensation followed by selenation with Woollins' reagent. 